\title{
Comparative Evaluation of Graham's Omentopexy Versus Modified Graham's Omentopexy in Perforated Duodenal Ulcers
}

\author{
Muhammad Ayub Jat
}

\begin{abstract}
Perforated peptic ulcer is a serious and the most frequent complication of peptic ulcer disease which demands urgent diagnostic procedure, reanimation and surgical intervention.

Objective: To compare Graham's omentopexy versus modified Graham's omentopexy in perforation of duodenum due to peptic ulcer disease in terms of postoperative complications and better outcome.

Patients and Methods: This randomized control trial study had included 84 cases of perforation of duodenum due to peptic ulcer disease which were randomized by using random number table into two groups Graham's Omentopexy 42 cases group A and modified Graham's Omentopexy 42 cases group B. The Patients with gastric perforation or other parts of the bowel were excluded. The present study was conducted in the Department of Surgery, at Ghulam Muhammad Mahar Medical College Sukkur from May 2009 to April 2012. All patients were post operatively followed-up for the period of 12 months at outpatients department.
\end{abstract}

\footnotetext{
${ }^{1}$ Assistant Professor Gen Surgery

College of Medicine, Northern Border University, Ar'ar, Kingdom of Saudi Arabia
}

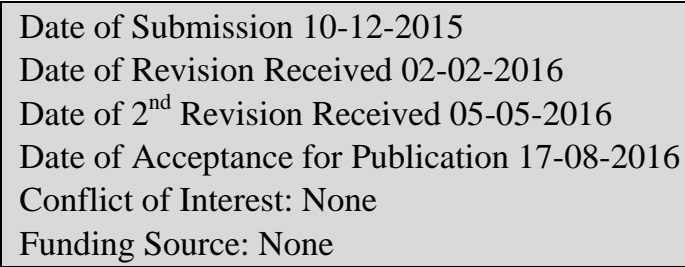

\section{Contribution}

All Authors have contributed in Study Design, Data Collection, Data Analysis, Data Interpretation, Manuscript Writing and Approval.
Results: Out of 84 patients, $76\{90.5 \%\}$ were males and $8\{9.5 \%\}$ were females with $\mathrm{M}$ : F ratio 9.5:1. The peak age of patients at presentation was between $30-$ 49 years $(61.8 \%)$. In group A Graham's omentopexy there was wound infection in 13 cases $\{30 \%\}$ biliary leakage in 2 cases $(4.6 \%\}$,intra-abdominal abscess in 2 cases $(4.6 \%)$ and 4 patients died $(9.5 \%$ but in group B modified Graham" omentopexy, wound infection was noted in 9 cases $(21.3 \%)$ but there was no biliary leakage and intra-abdominal abscess .There was three mortalities $(7.1 \%$ \} in group B. The average in- patients hospital stay in group A Graham's omentopexy was 11.5 days and in group B modified Graham's omentopexy 10.0 days.

Conclusion: Patients undergoing modified Graham's omentopexy in perforated duodenal ulcer had lesser post-operative complications and a shorter hospital stay with better outcome than Graham's omentopexy. Key Words: Peptic ulcer, duodenal perforation, Graham's omentopexy, modified Graham's omentopexy.

\section{Introduction}

Perforation is one of the most catastrophic complications of peptic ulcer disease. In spite of modern advances in surgical, anesthetic and ancillary facilities, it still assumes life threatening dimensions. The perforation occurs in $2-10 \%$ of patients and is often the first clinical presentation of peptic ulcer disease and accounts for more than $70 \%$ of deaths associated with perforated ulcer disease. ${ }^{2}$ The perforation site usually involves the anterior wall of the duodenum first part (60\%), antrum $(20 \%$ ) and lesser - curvature gastric ulcers $(20 \%))^{3}$ There is a changing trend in emergency surgery for perforated duodenal ulcer from definitive ulcer surgery to simple closure with omentopexy.

In 1937 the Graham's / omental patching began when Roscoe Graham of Toronto reported 51 cases of 
perforated peptic ulcer successfully treated with an omental patch laid over three sutures which are then tied being more than sufficient for closure of the duodenal perforation (without any attempt for primary closure of the perforation). ${ }^{3}$ Subsequent modifications came with the principal aim to close the perforation, keeping the omentum sandwiched between two layers of knots to prevent releaking (the major concern with Grahams' patch technique). ${ }^{5}$ The definitive surgical procedures have undergone many changes in the last half century, and the indications and the complications of each option are well known but declining in the popularity of them is quite obvious. Nowadays, primary suturing and Omental patch is a frequently selected procedure for perforated peptic ulcer. ${ }^{6}$

\section{Patients and Methods}

This randomized control trial study was conducted in Department of surgery at Ghulam Muhammad Mahar Medical College Sukkur from May 2009 to April 2012 which included 84 cases of perforation of first part of duodenum .The patients were randomized into two groups by using random number table, group A 42 cases Graham's omentopexy and group B 42 cases modified Graham's omentopexy. This study included only cases of perforation of first part of duodenum up to $2 \mathrm{~cm}$ in size and exclusion criteria were gastric perforation and perforation of first part of duodenum more than $2 \mathrm{~cm}$ in size.

All patients were admitted through emergency department and Clinical data were recorded in proforma. Blood chemistry and radiological investigations such as X-chest, ultrasound abdomen were carried out. .All patients on hospitalization received intravenous fluids, broad spectrum antibiotics, nasogastric aspirations, retained Foley catheter and timely monitoring of vital signs until surgical intervention. All operative findings and post-operative complications were recorded. All operations carried out under general or regional anesthesia. Upper midline incision was made in all cases. After confirmation of the site of perforation, peritoneal lavage was done with $4-5 \mathrm{~L}$ of warm normal saline. Special attention was paid to irrigate the sub hepatic pouch, the lesser sac, the paracolic gutters and pelvis. After the omentopexy, two drains, one in Morrison pouch and the other in pelvis, were placed and fixed. The midline abdominal wound was closed with mass closure technique.

Patients were randomized into groups while they were on operated table using random number table. Mostly the size of perforation was found between $0.5 \mathrm{~cm}$ to $1 \mathrm{~cm}(65 \%)$. The perforation of duodenum more than $2 \mathrm{~cm}$ in size was dealt with other surgical procedure i.e. Jejunal serosal patch and antrectomy .In Graham's omentopexy, 3 - 4 full thickness suture bites with $2 / 0$ vicryl were placed approximated $0.5 \mathrm{~cm}$ away from one margin to other sutures. A vascularized omental patch was laid over the sutures are successively tied from superior to inferior aspect across the omental patch to anchor the omental graft in place. In modified Graham's omentopexy, the perforation was closed with $2 / 0$ vicryl through and through sutures. The sutures were tied to approximate the wall defect without cutting through the duodenal wall. Then a vascularized segment of omentum brought on top of the closed perforation and with second set of sutures. Both groups were compared in terms of post-operative complications and surgical outcome. Post-operatively, all patients were prescribed for 2 weeks treatment of standard triple drugs therapy to eradicate Helicobacter pylori. All patients were followed-up for the period of 12 months in out - patients department.

\section{Results}

In this study total number of patients were 84 among them 76 males $(90.5 \%)$ and 8 were female $(9.5 \%\}$ the patient's age ranged from $20-65$ years with a mean age of 45 years. The age distribution of patients was showed in table 1 .

This study showed all patients had perforation anteriorly on the first part of duodenum with peritoneal contamination. The variable size of duodenal perforation was showed in table 2 .

Table 1: The age distribution of the patients.

\begin{tabular}{|c|c|c|}
\hline Age (Years) & No of patients & Percentage \\
\hline $20-29$ & 8 & $9.5 \%$ \\
\hline $30-39$ & 24 & $28.5 \%$ \\
\hline $40-49$ & 28 & $33.3 \%$ \\
\hline $50-59$ & 15 & $17.8 \%$ \\
\hline$>60$ & 9 & $10.7 \%$ \\
\hline
\end{tabular}


Table 2: The variable size of duodenal perforation.

\begin{tabular}{|c|c|c|}
\hline $\begin{array}{c}\text { Size of Duodenal } \\
\text { Perforation }\end{array}$ & No of Patients & Percentage \\
\hline$<0.5 \mathrm{~cm}$ & 16 & $19 \%$ \\
\hline $0.6-1 \mathrm{~cm}$ & 54 & $64.4 \%$ \\
\hline$>1 \mathrm{~cm}$ & 14 & $16.6 \%$ \\
\hline
\end{tabular}

The post-operative complications in group A Graham's omentopexy were wound infection in 13 cases (30\%), biliary leakage in 2 cases $(4.6 \%)$, intra-abdominal abscesses in 2 cases (4.6\%) and 4 patients died $(9.5 \%)$ but in group B modified Graham's omentopexy wound infection was noted in 9 cases $(21.3 \%)$ but there was no biliary leakage and intra-abdominal abscess . There were three mortalities $(7.1 \%)$ in group B. The hospital stay in group A was 11.5 days and in group B 10.0 days. The postoperative complications of both techniques was showed in table 3 .

\section{Discussion}

With the introduction of $\mathrm{H} 2$-receptors blockers and proton pump inhibitor elective surgery of peptic ulcers has decreased but the incidence of perforation and mortality rates has showed little change. ${ }^{7}$ The surgical methods for the treatment of peptic ulcer perforation are many and varied. Primary repair re-gained popularity because of the effectiveness of medical therapies in perforated duodenal ulcer. ${ }^{8}$ In this study 84 patients of perforated duodenal ulcer were included out of them $76(90.5 \%$ \} were males and $8(9.5 \%)$ were females (male: female $9.5: 1$ ) similar to other studies by Nishikant Gujar et al, male were (86\%), female (14\%) where the M: F ratio ranged from $6.15: 1$ to $9: 1 .{ }^{910}$ The peak age of patients at presentation was between $30-49$ years $(61.8 \%)$ with a mean age 45 years which differs significantly from other studies from Africa that had an average of $64.8+/-11.4$ years and from India highest incidence was between $40-60$ years. ${ }^{9,10}$ In this study out of 84 patients 48 (57\%) patients had past history of peptic ulcer disease and $36(43 \%)$ patients presented as duodenal ulcer perforation without history of Peptic ulcer disease, similar result $47 \%$ was reported by Lawal et al and by Nishikant et al, $45 \% .{ }^{112}$ The size of the perforation determines the amount of peritoneal contamination. The perforation more than $1 \mathrm{~cm}$ has incidence of leakage, morbidity and mortality when compared with small perforation. ${ }^{13}$ In this study we found 70 patients $(83.4 \%$ \} had perforation within range $0.1-1 \mathrm{~cm}$ in size similar result showed in other study by Nishikant et al 133 patients $(71.5 \%)$ had perforation within range $0.1-0.9 \mathrm{~cm}$. The study by A Nuhu et al, ${ }^{14}(82.7 \%$ ) patients had massive perforation, more than $1 \mathrm{~cm}$ but our series the perforation more than $1 \mathrm{~cm}$ was only in 14 cases (16.6\%). In our study the major postoperative complications in group A Graham's omentopexy was wound infection in 13 cases $\{30 \%\}$ biliary leakage in 2 cases (4.6\%), intra-abdominal abscess in 2 cases $(4.6 \%)$ but in group B modified Graham's omentopexy wound infection was noted in 9 cases $(23.3 \%)$ but there was, no biliary leakage and intra-abdominal abscess. The similar results of post -operative complications were also shown in other studies by Raj put et $\mathrm{al}^{15}$ and Sat apathy et al. ${ }^{16}$

In this study mortality rate is less $3(7.1 \%$ ) in group B modified Graham's omentopexy than $4(9.5 \%$ ) in group A Graham's omentopexy. The overall mortality rate was $8.3 \%$ associated with late presentation while in other studies by A Nuhu et al, ${ }^{14}$ all was $16.4 \%$ and

Table 3: The post-operative complications of both techniques.

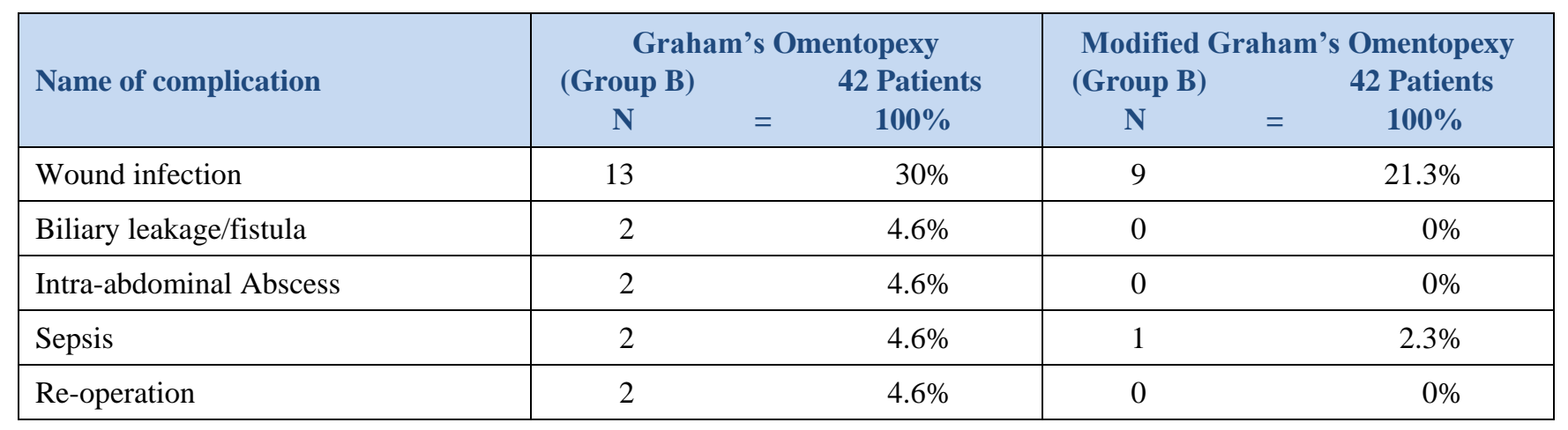


Sat apathy et al, ${ }^{16}$ all was $4.09 \%$. In another study by Umran_Muslu et al, the mortality rate is 5 patients $(3.9 \%) .{ }^{17}$ Mortality rate in literature varies with the range of $6.5-20 \% .^{18}$ In our series hospital stay was 11.5 days in group A Graham's omentopexy and 10.0 days in group B modified Graham's omentopexy similar in other series the average hospital stay was $9 \pm 1.2$ days. ${ }^{16}$ The hospital stay varies with the size of perforation, duration of illness and the condition of the patient on arrival. ${ }^{19}$ Several literatures support the role of therapy for $\mathrm{H}$. pylori in post-operative period. ${ }^{20} \mathrm{H}$. pylori eradication speeds up healing and decrease the relapse rate of ulcer disease as reported by Sebastian et al. ${ }^{21}$ Therefore Post-operatively, all patients were prescribed for a $2-3$ week course of standard triple drugs anti-H. Pylori therapy. In follow-up of 12 months one patient from Graham's omentopexy group A was readmitted with recurrence of symptoms and in modified Graham's omentopexy group B had better outcome without any recurrence. The most important factors predisposing to complications are delay in admission to the hospital, associated diseases and shock on admission. Mortality and morbidity can be reduced by early admission, prompt resuscitation, and treatment of associated diseases, early surgical intervention and prophylaxis of complications.

\section{Conclusion}

The present study showed that patients undergoing modified Graham's omentopexy in perforated duodenal ulcer had lesser post-operative complications and a shorter in-patients hospital stay with better outcome than Graham's omentopexy.

\section{References}

1. Gutierrez de La pena C, Merquez R, Fakih F, Dominguez - Adame E, Medina J. Simple closure or vagotomy and pyloroplasty for the treatment of a perforated duodenal ulcer comparison of results. Dig surg. 2000; 6: 225. doi: 10.1159/000018839.

2. Druart ML, Van Hee R, Etienne J. Laparoscopic repair of perforated duodenal ulcer: a prospective multicenter clinical trial. Surg Endosc. 1997; 11: 1017-1020.

3. Zittle TT, Jehle Ec, Becker HD. Surgical management of peptic ulcer disease today: indication, technique and outcome Langenbecks Arch Surg. 2000; 385: 84-96.

4. Graham RR. Treatment of perforated duodenal ulcers. Surge Gynecol Obstet. 1937; 64: 235-8.
5. Kumar K, Pai D, Srinivasan K, jagdish S, Ananthakrishnan N. Factors contributing to releak after surgical closure of perforated duodenal ulcer by Graham's Patch. Trop Gastroenterology, 2002; 23: 190-2.

6. Tsugawa K, Koyanagi N, Hashizume M, Tomikawa M ,Akahoshi K, Ayukawa K, Wada H, Tanoue K, Sugimachi K. The therapeutic strategies in performing emergency surgery for gastrodudenal ulcer perforation in 130 patients over 70 years of age. Hepatogastroenterology, 2001; 48: 156-62.

7. Christensen A, Bousfield R, Christensen J. Incidence of perforated and bleeding peptic ulcers before and after the induction of $\mathrm{H}_{2}$ - receptor antagonists. Ann Surg. 1998; 207: 4-6.

8. Jamieson GG. Current status of indications for surgery in peptic ulcer disease. World J Surg. 2000; 24: 256-8.

9. Plummer JM, McFarlane ME, Newnham. Surgical management of perforated duodenal ulcer; the changing scene West Indian Med J. 2004; 53: 378-81.

10. Nishikant, Jilani, Mudhol S. Contractor, Ravikumar Choudhari and Sushila Garag. Immediate Results of Omentopexy in Perforated Duodenal Ulcer: A Study of 186 Cases Al Ame en J Med Sci. 2012; 5 (1): 29-38.

11. Ohene - Yeboah M, Togbe B. Perforated gastric and duodenal ulcers in an urban African population. WEST Afar J Med. 2006; 25: 205-11.

12. Lawal O, Fadiran OA, Oluwale SF, Campbell B. Clinical pattern ofperforated prepyloric and duodenal ulcer at lle-lfe, Nigeria. Trop Doct. 1998; 28: 152-5.

13. Subedi SK, Afaq A, Adhikary S, Niraula SR, Agrawal CS. Factors influencing mortality in perforated duodenal ulcer following emergency surgical repair. J Nepal M Assoc. 2007; 46: 31-5.

14. A Nuhu, Madziga, B Gali. Acute perforated duodenal ulcer In Maiduguri. The Internet Journal of Surgery, 2008.

15. Rajput IA, iqbal M, Manzar S. Comparison of omentopexy techniques forduodenal perforation. Pak J Surg. 2000; 16: 1-4.

16. Mani Charan Satapathy, Dharitri Dash, Charan Panda Modified Grahams, omentopexy in acute perforation of first part of duodenum; A tertiary level experience in South India Saudi Surgical Journal, September December, 2013.

17. Ümran Muslu, Ali Kağan Gökakın, Ayşegül Demir, Orhan Üreyen, Özcan Altınel, Eyüp Sabri Tezcan, Mustafa Atabey, Gündüz Akgöl, Hüdai Genç. Mortality and Morbidity Risk factors in surgery of peptic ulcer perforation. Cumhuriyet Med J. 2012; 34: 189193.

18. Pai D, Sharma A, Kanungo R, Jagdish S, Gupta A. Role of abdominal drains in perforated duodenal ulcer patients: A prospective controlled study. Aus. N Z J Surg. 1999; 69: 210-3.

19. Arveen S, Jagdish S, Kadambari D. Perforated peptic 
ulcer in South India: An institutional perspective. World J Surg. 2009; 33: 1600-4.

20. Ng EK, Chung SC, Sng JJ, Lan YH, Lee DW, Lau JY. High prevalence of Helicobacter pylori infection in duodenal ulcer perforations not caused by non-ste- roidal anti-inflammatory drugs . Br J Surg. 1996; 83: 1779-81.

21. Sebastian M, Chand ran VP, Elashaal YI, Sim AJ. Helicobacter pylori infection in perforated peptic ulcer disease. Br J Surd. 1995; 82: 360-2. 